\title{
Kandidemi Olgularında Candida Türlerinin Dağılımı ve Sağ Kalıma Etki Eden Faktörlerin Belirlenmesi
}

\section{Distribution of Candida Species and Determination of Factors Affecting Survival in Patients with Candidemia}

\author{
${ }^{1}$ Aziz Ahmad HAMIDİ, ${ }^{2}$ Cüneyt KURU \\ ${ }^{1}$ Karabük Üniversitesi, Tıp Fakültesi, Enfeksiyon Hastalıkları ve Klinik Mikrobiyoloji Anabilim Dalı KBÜ, Karabük Eğitim ve Araştırma \\ Hastanesi Sirinevler, Merkez, Karabük \\ ${ }^{2}$ Karabük Üniversitesi, Tıp Fakültesi, Tıbbi Mikrobiyoloji Anabilim Dalı KBÜ, Karabük Eğitim ve Araştırma Hastanesi Şirinevler, \\ Merkez, Karabük
}

\section{ÖZ}

Amaç: Bu çalışmada, kandidemide etkenlerin dağgl1$\mathrm{m}$, risk faktörleri ve olguların sağ kalımına etki eden faktörlerin incelenmesi amaçlanmıștır.

Materyal ve Metot: Ocak 2016-Haziran 2019 tarihleri arasında kan kültüründe Candida türleri üreyen erişkin hastalar çalıșmaya alınmıștır. Kan kültür şișeleri BACTEC FX-40 (Becton Dickinson, MD, ABD) tam otomatize kan kültür sisteminde inkübe edilmiştir. Kolonilerin tanımlanmasında Phoenix TM (Becton Dickinson Diagnostics, ABD) otomatize sistem kullanılmıştır. Hastaların klinik özellikleri hastane kayıtlarından geriye dönük olarak incelenmiştir.

Bulgular: Candida türleri, 114 hastadan alınan 261 kan kültürü örneğinde saptanmıştır. Bu hastalarda, 122 kandidemi atağ 1 tespit edilmiștir. Klinik özelliklerine ulaşılan 75 hasta incelenmiştir. Olguların \%66,6'sı kadın, yaş ortalamas $14,35 \pm 14,34$ y1l ve mortalite oran $\% 70,7$ idi. Atakların \%57'sinde C. albicans üredi. C. albicans ve non-albicans Candida (NAC) üreyen olgularda, klinik bulgular ve risk faktörleri açısından istatistiksel olarak anlamlı bir fark saptanmadı. Otuz günlük sağ kalım açısından, yoğun bakım biriminde yatış, mekanik ventilasyon, bakteriyemi ve uzun yatış süresi sağ kalan grupta daha yüksek bulunmuştur.

Sonuç: Kandidemi olgularının yoğun bakım biriminde izlenmesinin, hastaların sağ kalımına olumlu etki yaptığını düşünmekteyiz

Anahtar Kelimeler: İnvazif kandidiyaz, kandidemi, sağ kalım oranı

\section{ABSTRACT}

Objective: It is aimed to analyze the distribution of agents, risk factors and factors affecting survival in candidemia.

Materials and Methods: We included adult patients who produced Candida spp. in the blood culture between January 2016 and June 2019 to study. Blood culture bottles were incubated in the BACTEC FX-40 (Becton Dickinson, MD) fully automated blood culture system. Phoenix TM (Becton Dickinson Diagnostics) automated system was used to identify the colonies. The clinical features of the patients were retrospectively determined from the hospital records.

Results: Candida species were detected in 261 blood culture samples taken from 114 patients. In these patients, 122 attacks of candidemia were detected. 75 patients who were having clinical findings were reached. $66.6 \%$ of the cases were female, mean age was $74.35 \pm 14.34$ and mortality rate was $70.7 \%$. C. albicans growth in $57 \%$ of the attacks. There was no statistically significant difference in terms of clinical findings and risk factors in cases which C. albicans and non-albicans candida (NAC) growth. In terms of the 30-day mortality, hospitalization in intensive care unite (ICU), mechanical ventilation, bacteraemia and long hospitalization duration were found higher in the surviving group.

Conclusions: We think that monitoring candidemia cases in the ICU has a positive effect on patients' survival. Keywords: Candidemia, invazive candidiasis, survival rate

\footnotetext{
Sorumlu Yazar / Corresponding Author:

Aziz Ahmad Hamidi

KBÜ, Karabük Eğitim ve Araştırma Hastanesi Şirinevler, Merkez, Karabük

Tel: +905326974002

E-mail: azizahmadhamidi@gmail.com
}

\section{Yayın Bilgisi / Article Info:}

Gönderi Tarihi/ Received: 28/05/2020

Kabul Tarihi/ Accepted: 02/07/2020

Online Yayın Tarihi/ Published: 30/09/2020

Atıf / Cited: Hamidi AA ve Kuru C. Kandidemi olgularında Candida türlerinin dağılımı ve sağ kalıma etki eden faktörlerin belirlenmesi. Online Türk Sağllk Bilimleri Dergisi 2020;5(3):474-481. doi: 10.26453/otjhs.744639 


\section{GÍRIŞ}

Hastanede özellikle yoğun bakım birimi (YBB)'nde yatan hastalarda, Candida türlerinin neden olduğu kan dolaşımı infeksiyonu önemli bir mortalite ve morbidite nedenidir. $^{1-3}$

Çeşitli nedenlere bağlı olarak hastaların uzun süre YBB'nde kalması, bağışıklık sistemini baskılayan ilaçların uygulanması ve invazif aletlerin artan oranda kullanılması sonucunda, kandidemi insidansı yıllar içinde giderek artmaktadır. ${ }^{4}$ Total parenteral nütrisyon (TPN) gereksinimi, santral venöz kateter (SVK) kullanımı, kortikosteroid veya diğer immunosupressif ilaçların uygulanması, bakteriyel infeksiyonun eşlik etmesi, mekanik ventilasyon ve geçirilmiş ameliyat varlığ kandidemi için risk oluşturmaktadır. ${ }^{5-8}$ Son yıllarda yapılan çalışmalara göre nonalbicans Candida (NAC) türlerinin sıklığı artmıştır. ${ }^{2,5,9}$ Altta yatan hastalığın varlığı ve şiddeti, uygun olmayan antifungal tedavi SVK varlığ ve hastanın uzun süre YBB'nde kalması gibi faktörlerin varlığı mortalite oranını artırmaktadır. Mortalite oranı çalışmalarda \%38-55 arasında değişmekte olup özellikle NAC türlerinin neden olduğu olgularda mortalite belirgin olarak artmaktadır. ${ }^{10-13}$ Ülkemizde daha önce yapılan kimi çalışmalarda NAC türleri daha sık saptanırken, kimisinde ise ağırlıklı etken olarak $C$. albicans bulunmuştur. , $^{3,8,14}$

$\mathrm{Bu}$ çalışmada, kan dolaşımı infeksiyonu etkeni olan Candida türlerinin dağılımının saptanması, risk faktörlerinin belirlenmesi, olguların klinik özellikleri ve sağ kalıma etki eden faktörlerin irdelenmesi amaçlanmıştır.

\section{MATERYAL VE METOT}

Çalışma için Karabük Üniversitesi Tıp Fakültesi Girişimsel Olmayan Klinik Araştırmalar Etik Kurulu'ndan etik kurul onayı alındı (Tarih: 05/03/2020, karar no: 188).

Ocak 2016-Haziran 2019 tarihleri arasında Karabük Üniversitesi Eğitim ve Araştırma Hastanesi'nde yatarak tedavi gören hastalardan mikrobiyoloji laboratuvarına gönderilen kan kültürü örneklerinde kandida üremesi olanlar çalışmaya dahil edildi. Kan kültür şişeleri BACTEC FX-40 (Becton Dickinson, MD, ABD) tam otomatize kan kültür sisteminde yedi gün süreyle inkübe edildi, pozitif sinyal veren şişelerden koyun kanlı agar, EMB agar ve çikolata agara ekim yap 1 ld $1.37^{\circ} \mathrm{C}$ 'de 24 saat inkübe edilen plaklarda üreyen kolonilerden yapılan Gram boyamasında maya görülenlerden Sabouraud dekstroz agara (SDA) pasaj yapıldı. 24 saatlik inkübasyon sonrasın- da üreyen kolonilerin tanımlanmasında Phoenix ${ }^{\text {TM }}$ (Becton Dickinson Diagnostics, ABD) otomatize sistem kullanıldı.

Onsekiz yaştan küçük hastalar ve dış merkezden gelen örnekler çalışma dışı bırakıldı. Kan kültüründe Candida türleri üreyen olgularda sonraki 15 gün içinde pozitif sonuçlanan diğer kan kültürü örnekleri aynı atak içinde değerlendirildi. Üreme zamanına göre kandidemi ataklarının tespit edilerek hastaların klinik ve laboratuvar özellikleri geriye dönük olarak incelendi.

Hastaların yaş, cinsiyet, yattığ 1 birim gibi özelliklerinin yanı sıra üriner kateter (ÜK), nazogastrik sonda (NG), mekanik ventilasyon (MV), TPN, SVK, geçirdiği batın ameliyatı ve kronik böbrek yetmezliği gibi risk faktörlerinin olup olmadığı hastane kayıtlarından ve hasta dosyalarından geriye dönük olarak saptandi.

Hastaneye yatış anından kan kültüründe Candida türlerinin ürediği zamana kadar geçen süre yatış süresi olarak tanımlandı. Kandidemiden 15 gün önceki süre içinde kan kültüründe bakteri üreyen olgular, bakteriyemi eşlik etmiş olarak kabul edildi. Kandidemi geliştiği süreden bir hafta öncesine kadar geçen sürede idrar kültüründe kandida üreyen olgularda kandidüri olarak tanımlandı. Kan kültüründe kandida üredikten sonraki 30 gün içinde gerçekleşen ölüm, kandidemiye atfedilen ölüm olarak tespit edildi. Buna göre 30 günlük mortalite hesaplandı. Otuz günlük mortalite oranına göre ölen ve sağ kalan olgular, risk faktörleri ve klinik özellikleri açısından karşılaştırıldı. Ayrıca C. albicans ve NAC türlerinin etken olduğu olguların özellikleri karşılaştırıldı.

Verilerin istatistiksel analizi için, İstatistiksel Paket (SPSS Inc.; Chicago, IL, ABD) 15.0 Windows programı kullanıld. Tanımlayıcı istatistikler ortalama, standart sapma, medyan, minimun ve maksimum kullanıldı. Kategorik değişkenler için Ki-Kare testi, normal dağılım gösteren değişkenler için Student ttesti kullanıldı. Dağılımı normal olmayan sürekli varyasyon gösteren değişkenlerde Mann Whitney U istatistiksel analizleri yapıldı. $\mathrm{P}<0.05$ istatistiksel olarak anlamlı kabul edildi.

\section{BULGULAR}

Çalışma süresi içinde 261 kan kültürü şişesinden Candida türleri izole edilmiştir. $\mathrm{Bu}$ örneklerin gönderildiği 114 hastadan bazısında birden çok kandidemi atağı gelişmiş olup toplamda 122 kandidemi atağı saptanmıştır. Olguların 75 'inin risk faktörlerini içeren klinik bulgularına ulaşılmıştır. Klinik bulgu- 
larına ulaşılan olguların \%66,6'sı kadın, yaş ortalamas1 74,35 $\pm 14,34$ y1l ve mortalite oran1 \%70,7 olarak saptanmıştır. Olguların \%85,3'ünde YBB'nde izlendiği sırada kandidemi geliştiği tespit edilmiştir. Hastaların özellikleri tablo 1'de gösterildi. Tespit edilen 122 kandidemi atağının $69(\% 57)$ 'u C. albicans, 21 (\%17)'i C. parapsilosis, 19 (\%16)'u $C$. tropicalis, dokuzu (\%7) C. glabrata, üçü (\%2) C. krusei ve biri $(\% 1) \quad C$. lusiteniae olduğu saptanmıştır. Atakların \%57'sinde C. albicans saptanırken \%43'ünde NAC türleri saptanmıştır. Kan kültüründe $C$. albicans ve NAC türleri üreyen olguların özellikleri karşılaştırıldığında iki grup arasında istatistiksel açıdan anlamlı bir fark saptanmadı (Tablo 2). Otuz günlük mortalite oranına göre kandidemi atağında ölen ve sağ kalan hastaların özellikleri karşılaştırıldı. Sağ kalan grupta YBB'nde olma durumu, ölen gruba göre daha yüksek bulundu $(\mathrm{p}=0,021)$. Ayrıca sağ kalanlarda MV, bakteriyemi varlığı ve yatış süresi daha yüksek bulundu (sırasıyla $p=0,019 ; p=0,003 ; p=0,02)$. Ölen ve sağ kalanların özellikleri tablo 3 'te gösterildi.

\section{TARTIŞMA VE SONUÇ}

Çalışmamızda olguların yaş ortalamasının $(74,35)$ yüksek olduğu ve kadın cinsiyetinin $(\% 66,6)$ ön planda olduğu gözlenmiştir. Çalışmamızdan farklı olarak önceki çalışmalar, yaş ortalamasını daha düşük ve erkek cinsiyet oranını daha yüksek olarak belirtmiştir. ${ }^{3,5,14}$ Yapılan kontrollü çalışmalar, YBB'nde invazif alet kullanımının kandidemi riskini artırdığını göstermiştir. ${ }^{1,2,7,8}$ Çalışma olgularımızda da invazif alet kullanımının (özellikle SVK oranı \% 86,7) yüksek olduğu görülmüştür. Çalışmamızda 30 günlük mortalite oranı $(\% 70,7)$ da önceki çalışmalara göre yüksek bulunmuştur. ${ }^{3,5,8,15}$ Daha önce yapılan çalışmalara göre; ileri yaş, YBB'nde olmak ve altta yatan hastalığın şiddetli olması mortalite için bağımsız risk faktörleridir. ${ }^{12,16-20}$ Olgularımızın \% 85,3'ünün YBB'nde olması ve yaş ortalamasının yüksek olması yüksek mortalite oranıyla ilişkili olabilir. Ancak çalışmamızda ölen ve sağ kalan olguların karşılaştırılması sonucunda; uzun süre yatış öyküsü, MV varlığı, YBB'nde takip edilmiş olması ve bakteriyemi varlığı sağ kalan olgularda belirgin olarak daha yüksek bulundu. Bu bulgu literatürdeki bilgilerden farklı idi. Bununla birlikte Ishikane ve ark.nın ${ }^{21}$ yaptığı çalışmaya göre, kandidemisi olan olgularda rutin İnfeksiyon Hastalıkları konsültasyonu \%46 oranında mortalitede azalmaya neden olmuştur. Hastanemizde YBB'nde yatan ve MV destegi alan olgulara, İnfeksiyon Hastalıkları ve Klinik
Mikrobiyoloji uzmanı tarafından günlük vizit yapılmaktadır. Benzer biçimde bakteriyemi gelişen olgular antibiyotik kullandığından daha yakından izlenmektedir. Ayrica uzun süre YBB'nde yatan hastalarda sürveyans kültürleri yapılmaktadır. Bu şekilde yakından izlenen bu olgular, daha hızlı tanı ve antifungal tedavi imkanına ulaşmaktadırlar. Bu durumun YBB'nde yatan olguların sağ kalım oranını olumlu etkilediğini düşünmekteyiz. Aksine servislerde takip edilen olgularda, kültür sonucu klinik doktoru tarafindan görüldükten ve konsültasyon talebi yapıldıktan sonra, konsültasyon sonucuna göre tedavi başlanmaktadır; bu sebeple antifungal tedavi YBB hastalarına göre daha geç başlanmaktadır. Olgularda kandidürinin saptanması kandidemi için bağımsız bir risk faktörü değildir. ${ }^{22,23}$ Ancak bizim olgularımızın \%96'sında kandidüri saptanmıştır. Bu bulgu literatürdeki bilgilerden farklı olarak daha yüksek bulunmuştur.

Son yıllarda yapılan çalışmalarda kan dolaşımı infeksiyonuna neden olan Candida türlerinden NAC türlerinin daha sık olduğu ve flukonazole direnç oranının daha yüksek olduğu görülmüştür. ${ }^{2,24,25}$ Diğer yandan NAC türleri arasında $C$. tropicalis en kötü prognoza sahip olduğu saptanmıştır. ${ }^{10}$ Çalışmamizda, NAC türleri \%43 iken C. tropicalis tüm etkenlerin \%16'sını oluşturmaktadır. Sun ve ark.nın ${ }^{26}$ yaptığı bir çalışmada TPN kullanımı C. parapsilosis kandidemisi için bağımsız bir risk faktörü olarak saptanmıştır. İmmunosupresif tedavisi, daha önce azol, kinolon, beta laktamaz inhibitörlü beta laktam grubu antibiyotik kullanımı ve SVK varlığı NAC türleriyle olan kandidemi için bağımsız risk faktörü olarak saptanmıştır. ${ }^{27,28}$ Çalışmamızda, C. albicans ve NAC türlerinin etken olduğu olgularda invazif alet kullanımı ve risk faktörleri açısından belirgin bir fark saptanmamıştır.

Çalışmamızın retrospektif olması, olgularda altta yatan hastalığın şiddetinin tespit edilmemiş olması ve üreyen Candida türlerinde antifungal duyarlılık testlerinin yapılmamış olması çalışmamızın kısıtlayıc1 yönleridir.

Sonuç olarak çalışmamız, Candida türleriyle oluşan kan dolaşımı infeksiyonunda en sık etkenin hâlâ $C$. albicans olduğunu, kandideminin yüksek mortaliteye neden olduğunu, $C$. albicans ve NAC türlerinin neden olduğu kandidemi olgularında invazif alet kullanımı ve risk faktörleri açısından fark bulunmadığını göstermiştir. Ek olarak YBB'nde izlenen, uzun süre hastane yatışı olan, MV desteği alan ve öncesinden bakteriyemi gelişen olgular, sağ kalan grupta belirgin olarak daha yüksek bulunmuştur. $\mathrm{Bu}$ 
nedenle kandidemisi olan olguların YBB'nde izlenmesinin, hastaların sağ kalımına olumlu etki yapabileceğini düşünmekteyiz.

Etik Komite Onayı: Çalışma için Karabük Üniversitesi Tıp Fakültesi Girişimsel Olmayan Klinik Araştırmalar Etik Kurulu'ndan etik kurul onayı alındı (Tarih: 05/03/2020, karar no: 188).

Çıkar çatışması: Yazarlar çıkar çatışması bildirmemişlerdir.

Yazar katkıları: Fikir - A.A.H., C.K; Denetleme A.A.H., C.K; Malzemeler - A.A.H., C.K; Veri toplanması ve işlenmesi - A.A.H., C.K; Analiz ve yorum - A.A.H., C.K; Yazıyı yazan - A.A.H., C.K

Hakem Değerlendirmesi: Dış bağımsız.

\section{KAYNAKLAR}

1. Atamna A, Eliakim-Raz N, Mohana J, et al. Predicting candidemia in the internal medicine wards: a comparison with gram-negative bacteremia-a retrospectives study. Diagn Microbiol Infect Dis. 2019;95(1):80-83.

2. Da Silva RB, Neves RP, Hinrichsen SL, de Lima-Neto RG. Candidemia in a public hospital in Northeastern Brazil: Epidemiological features and risk factors in critically ill patients. Rev Iberoam Micol. 2019;36(4):181-185.

3. Erdem I, Oguzoglu N, Ozturk Engin D, et al. Incidence, etiology and risk factors associated with mortality of nosocomial candidemia in a tertiary care hospital in Istanbul, Turkey. Med Princ Pract. 2010;19(6):463-467.

4. Spiers R, Smyth B, Lamagni T, et al. The epidemiology and management of candidemia in Northern Ireland during 2002-2011, including a 12-month enhanced case review. Med Mycol. 2019;57(1):23-29.

5. Horn DL, Neofytos D, Anaissie EJ, et al. Epidemiology and outcomes of candidemia in 2019 patients: data from the prospective antifungal therapy alliance registry. Clin Infect Dis. 2009;48(12):1695-1703.

6. Berdal JE, Haagensen R, Ranheim T, Bjornholt JV. Nosocomial candidemia; risk factors and prognosis revisited; 11 years experience from a Norwegian secondary hospital. PLoS One. 2014;9(7):e103916.

7. Tukenmez Tigen E, Bilgin H, Perk Gurun H, et al. Risk factors, characteristics, and outcomes of candidemia in an adult intensive care unit in Turkey. Am J Infect Control. 2017;45(6):e61-e63.
8. Mermutluoglu C, Deveci O, Dayan S, Aslan E, Bozkurt F, Tekin R. Antifungal Susceptibility and Risk Factors in Patients with Candidemia. Eurasian J Med. 2016;48(3):199-203.

9. Israel $\mathrm{S}$, Amit $\mathrm{S}$, Israel A, Livneh A, Nir-Paz R, Korem M. The Epidemiology and Susceptibility of Candidemia in Jerusalem, Israel. Front Cell Infect Microbiol. 2019;9:352.

10. Ko JH, Jung DS, Lee JY, et al. Poor prognosis of Candida tropicalis among non-albicans candidemia: a retrospective multicenter cohort study, Korea. Diagn Microbiol Infect Dis. 2019;95(2):195-200.

11. Luzzati R, Cavinato S, Deiana ML, Rosin C, Maurel C, Borelli M. Epidemiology and outcome of nosocomial candidemia in elderly patients admitted prevalently in medical wards. Aging Clin Exp Res. 2015;27(2):131-137.

12. Medeiros MAP, Melo APV, Bento AO, et al. Epidemiology and prognostic factors of nosocomial candidemia in Northeast Brazil: A sixyear retrospective study. PLoS One. 2019;14 (8):e0221033.

13. Wisplinghoff H, Ebbers J, Geurtz L, et al. Nosocomial bloodstream infections due to Candida spp. in the USA: species distribution, clinical features and antifungal susceptibilities. Int J Antimicrob Agents. 2014;43(1):78-81.

14. Yılmaz G CA, Gunduz M, Ozen M, Saricaoglu EM, Akan H. Evaluation of Candida Species and Risk Factors in Haematologic Cancer Patient With Candidemia. Klimik Derg. 2015;28(3).

15. Karacaer Z, Oncul O, Turhan V, Gorenek L, Ozyurt M. A surveillance of nosocomial candida infections: epidemiology and influences on mortalty in intensive care units. Pan Afr Med J. 2014;19:398.

16. Orsetti E, Brescini L, Mazzanti S, et al. Central venous catheter unrelated candidemia influences the outcome of infection in patients with solid tumors. Eur J Clin Microbiol Infect Dis. 2019;38 (8):1499-1505.

17. Toda M, Williams SR, Berkow EL, et al. Population-Based Active Surveillance for CultureConfirmed Candidemia - Four Sites, United States, 2012-2016. MMWR Surveill Summ. 2019;68(8):1-15.

18. Yang ZT, Wu L, Liu XY, et al. Epidemiology, species distribution and outcome of nosocomial Candida spp. bloodstream infection in Shanghai. BMC Infect Dis. 2014;14:241. 
19. Ala-Houhala M, Valkonen M, Kolho E, Friberg N, Anttila VJ. Clinical and microbiological factors associated with mortality in candidemia in adult patients 2007-2016. Infect Dis (Lond). 2019;51(11-12):824-830.

20. Hesstvedt L, Gaustad P, Muller F, et al. The impact of age on risk assessment, therapeutic practice and outcome in candidemia. Infect Dis (Lond). 2019;51(6):425-434.

21. Ishikane M, Hayakawa K, Kutsuna $S$, Takeshita $\mathrm{N}$, Ohmagari N. The impact of infectious disease consultation in candidemia in a tertiary care hospital in Japan over 12 years. PLoS One. 2019;14 (4):e0215996.

22. Drogari-Apiranthitou M, Anyfantis I, Galani I, Kanioura L, Daikos GL, Petrikkos G. Association Between Candiduria and Candidemia: A Clinical and Molecular Analysis of Cases. Mycopathologia. 2017;182(11-12):1045-1052.

23. Bougnoux ME, Kac G, Aegerter P, d'Enfert C, Fagon JY, CandiRea Study G. Candidemia and candiduria in critically ill patients admitted to intensive care units in France: incidence, molecular diversity, management and outcome. Intensive Care Med. 2008;34(2):292-299.

24. Boan P, Gardam D. Epidemiology and antifungal susceptibility patterns of candidemia from a tertiary centre in Western Australia. J Chemother. 2019;31(3):137-140.

25. Papadimitriou-Olivgeris M, Spiliopoulou A, Kolonitsiou F, et al. Increasing incidence of candidaemia and shifting epidemiology in favor of Candida non-albicans in a 9-year period (20092017) in a university Greek hospital. Infection. 2019;47(2):209-216.

26. Sun M, Chen C, Xiao W, Chang Y, Liu C, Xu Q. Increase in Candida Parapsilosis Candidemia in Cancer Patients. Mediterr J Hematol Infect Dis. 2019;11(1):e2019012.

27. Ghanem-Zoubi N, Khoury J, Arnon M, Zorbavel D, Geffen Y, Paul M. Risk Factors for NonAlbicans Candidemia Focusing on Prior Antifungal and Immunosuppressive Therapy. Isr Med Assoc J. 2019;5(21):303-307.

28. Kofteridis DP, Valachis A, Dimopoulou D, et al. Factors Influencing Non-albicans Candidemia: A Case-Case-Control Study. Mycopathologia. 2017;182(7-8):665-672 
Tablo 1. Hastaların özellikleri ve risk faktörleri.

\begin{tabular}{|l|c|c|}
\hline Özellik (n=75) & $\mathbf{~ N ~}$ & \% \\
\hline Yaş (yı1) & $74,35 \pm 14,34$ & \\
\hline Yatış süresi (gün) & $34,59 \pm 2745$ & \\
\hline Cinsiyet & & \\
Erkek & 25 & 33,3 \\
Kadın & 50 & 66,6 \\
\hline Yoğun bakım yatışı & 64 & 85,3 \\
\hline Batın ameliyatı & 2 & 2,6 \\
\hline Mekanik ventilasyon & 54 & 72 \\
\hline Santral venöz kateter & 65 & 86,7 \\
\hline Total parenteral nütrisyon & 42 & 56 \\
\hline Üriner kateter & 65 & 86,7 \\
\hline Nazogastrik sonda & 38 & 50.6 \\
\hline Kronik böbrek yetmezliği & 5 & 6,7 \\
\hline Bakteriyemi varlığı & 38 & 50,7 \\
\hline Kandidüri & 72 & 96 \\
\hline Mortalite & 53 & 70,7 \\
\hline
\end{tabular}


Tablo 2. Albicans ve non-albicans Candida türleri üreyen olguların karşılaştırılması.

\begin{tabular}{|c|c|c|c|}
\hline Özellik & $\begin{array}{l}\text { C. albicans } \\
(\mathrm{n}=41)\end{array}$ & $\begin{array}{c}\text { *NAC türleri } \\
(n=34)\end{array}$ & $\mathbf{p}$ \\
\hline Yaş (ortalama yıl \pm Standart sapma) & $74,5 \pm 14,8$ & $74,2 \pm 13,8$ & 0,928 \\
\hline Yatış süresi (ortalama gün \pm Standart sapma) & $32,9 \pm 23,7$ & $36,6 \pm 31,2$ & 0,561 \\
\hline Cinsiyet n (\%) & & & \multirow{3}{*}{0,87} \\
\hline Erkek & $27(65,8)$ & $23(67,6)$ & \\
\hline Kadın & $14(34,2)$ & $11(32,4)$ & \\
\hline Batın ameliyatı öyküsü n (\%) & $2(4,9)$ & $0(0)$ & 0,192 \\
\hline Mekanik ventilasyon $\mathrm{n}(\%)$ & $29(70,7)$ & $25(73,5)$ & 0,788 \\
\hline Santral venöz kateter n (\%) & $33(80,5)$ & $32(94,1)$ & 0,084 \\
\hline Total parenteral nütrisyon $\mathrm{n}(\%)$ & $25(61,0)$ & $15(44,1)$ & 0,145 \\
\hline Üriner kateterizasyon $\mathrm{n}(\%)$ & $36(87,8)$ & $29(85,3)$ & 0,75 \\
\hline Nazogastrik sonda $\mathrm{n}(\%)$ & $20(48,8)$ & $18(52,9)$ & 0,72 \\
\hline Kronik böbrek yetmezliği n (\%) & $2(4,9)$ & $3(8,8)$ & 0,495 \\
\hline Bakteriyemi varlığı n (\%) & $22(53,7)$ & $16(47,1)$ & 0,569 \\
\hline Kandidüri varlığı n (\%) & $40(97,6)$ & $32(94,1)$ & 0,449 \\
\hline Mortalite oranı n (\%) & $28(68,3)$ & $25(73,5)$ & 0,62 \\
\hline
\end{tabular}

* Non-albicans Candida 
Tablo 3. Ölen ve sağ kalan olguların risk faktörleri ve klinik bulguları açısından karşılaştırılması.

\begin{tabular}{|c|c|c|c|}
\hline Özellik & $\begin{array}{c}\text { Ölen olgular } \\
(\mathrm{n}=53)\end{array}$ & $\begin{array}{c}\text { Sağ kalan } \\
\text { olgular } \\
(\mathbf{n}=22)\end{array}$ & $\mathbf{p}$ \\
\hline Yaş (ortalama yıl \pm Standart sapma) & $75,0 \pm 14,4$ & $72,8 \pm 14,2$ & 0,547 \\
\hline Yatış süresi (ortalama gün \pm Standart sapma) & $29,9 \pm 21,3$ & $45,8 \pm 35,9$ & $0,02 *$ \\
\hline $\begin{array}{l}\text { Cinsiyet n (\%) } \\
\text { Erkek } \\
\text { Kadın }\end{array}$ & $\begin{array}{l}36(67,9) \\
17(32,1)\end{array}$ & $\begin{array}{c}14(63,6) \\
8(36,4)\end{array}$ & 0,72 \\
\hline Batın ameliyatı öyküsü n (\%) & $2(3,7)$ & $0(0)$ & 0,356 \\
\hline Mekanik ventilatör n (\%) & $34(64,2)$ & $20(90,9)$ & $0,019^{*}$ \\
\hline Santral venöz kateter n (\%) & $45(84,9)$ & $20(90,9)$ & 0,486 \\
\hline Total parenteral nütrisyon $\mathrm{n}(\%)$ & $31(58,5)$ & $11(50)$ & 0,5 \\
\hline Üriner kateterizasyon $\mathrm{n}(\%)$ & $45(84,9)$ & $20(90,9)$ & 0,486 \\
\hline Nazogastrik sonda $\mathrm{n}(\%)$ & $25(47,2)$ & $13(59,1)$ & 0,347 \\
\hline Kronik böbrek yetmezliği n (\%) & $3(5,7)$ & $2(9,1)$ & 0,588 \\
\hline Bakteriyemi varlığı n (\%) & $21(39,6)$ & $17(77,3)$ & $0,003 *$ \\
\hline Kandidüri varlığı n (\%) & $51(96,2)$ & $21(95,5)$ & 0,877 \\
\hline C. albicans $\mathrm{n}(\%)$ & $28(52,8)$ & $13(59,1)$ & 0,62 \\
\hline Yoğun bakım biriminde yatış $\mathrm{n}(\%)$ & $42(79,2)$ & $22(100)$ & $0,021 *$ \\
\hline
\end{tabular}

$* \mathrm{p}<0,05$ 